Ethos (Jurnal Penelitian dan Pengabdian Masyarakat): 82-90

\title{
Studi Numerik 2-D Perpindahan PANas Aliran CRossflow Pada Silinder Sirkular Tunggal Dan TANDEM Dengan MOdifIKASI TuRbUlent Viscosity
}

\author{
2-D Numerical Study of Heat TRANSFer Crossflow on Single Circular Cylinder AND Tandem \\ WITH TURBULENT VISCOSITY MODIFICATION \\ ${ }^{1}$ Arif Kurniawan, ${ }^{2}$ Sibut, ${ }^{3}$ Mochtar Asroni, ${ }^{4}$ Teguh Rahardjo \\ ${ }^{1,2,34}$ FTI - Teknik Mesin, Institut Teknologi Nasional, Kampus 2 ITN Jl. Raya Karanglo KM. 2 Malang \\ e-mail: ${ }^{1}$ itsarif9@gmail.com, ${ }^{2}$ Sibutlay@yahoo.co.id, ${ }^{3}$ mochtar@fti.itn.ac.id, ${ }^{4}$ djo_tgr45@yahoo.com
}

\begin{abstract}
The crossflow in cylinder marked by the phenomenon of stagnation point, shear layer separation and wake formation. Characteristics of flow regimes can be unsteady laminar flow (the formation of vortex shedding regime), transitional (regime with the transition to turbulent flow pattern in the wake area) and subcritical (regime formation of the turbulent on shear layer). The value of the Reynolds number is very influential on the flow regimes characteristics of the flow, while the heat transfer process is heavily influenced by the value of Prandtl number. The amount of heat transfer is indicated by the parameter of Nusselt number. This study uses a numerical study by modifying the quantity of turbulent, ie the turbulent viscosity by interpreting UDF (user defined function). The results of numerical studies in the form of Nusselt number will be compared with the value of Nusselt number of experimental results and to create a basis consept for studying the mechanism of the flow phenomenon and heat transfer in the heat exchanger tube banks. The method used is a steady and unsteady 2-DRANS (Reynolds-averaged Navier Stokes) numerical simulations with 3 modeling, namely the standard $k-\epsilon$, standard $k-\omega$ and SST $k$ - $\omega$ turbulence models.
\end{abstract}

Keywords: RANS, UDF, Nusselt number, turbulent viscosity

\begin{abstract}
Abstrak. Aliran crossflow pada silinder ditandai dengan terjadinya fenomena titik stagnasi, separasi shear layer dan terbentuknya wake. Karakteristik flow regimes alirannya bisa berupa unsteady laminar (regime terbentuknya vortex shedding), transitional (regime dengan pola aliran transisi menuju turbulen pada daerah wake) dan sub-critical (regime terbentuknya turbulen pada shear layer). Besarnya nilai Reynolds number sangat berpengaruh pada karakteristik flow regimes aliran ini, sedangkan proses perpindahan panasnya banyak dipengaruhi oleh nilai Prandtl number. Besarnya nilai heat transfer ditunjukkan dengan parameter Nusselt number. Penelitian ini menggunakan studi numerik dengan memodifikasi kuantitas turbulen, yaitu pada turbulent viscosity dengan melakukan interpret UDF (user define function). Hasil studi numerik yang berupa Nusselt number akan dibandingkan dengan nilai Nusselt number hasil eksperimen dan dapat dijadikan basis konsep untuk mempelajari mekanisme fenomena aliran dan perpindahan panas pada tube banks heat exchanger. Metode penelitian yang digunakan adalah simulasi numerik 2-D RANS (Reynolds-Averaged Navier Stokes) steady dan unsteady dengan 3 pemodelan, yaitu standard $k-\epsilon$, standard $k-\omega$, dan SST $k-\omega$ turbulence model.
\end{abstract}

Kata kunci: RANS, UDF, Nusselt number, turbulent viscosity

\section{Pendahuluan}

Regime sub-critical berada pada range Reynolds number sekitar $300<\mathrm{Re}_{\mathrm{D}}<2 \times 10^{5}$ (Beaudan, P. dan Moin, P., 1994). Pada regime ini akan terjadi turbulent wake, separasi 
shear layer, periodic vortex dan untuk Reynolds number yang cukup tinggi akan terbentuk laminar boundary layer yang terseparasi di upstream silinder sirkular dengan kondisi karakteristik aliran yang cenderung turbulen. Nilai Strouhal numbernya konstan pada $\mathrm{St}= \pm 0.2$.

Dari hasil studi dan penelitian tentang periodic vortex (Kieft, R., et.al., 2007), proses terjadinya diawali dengan adanya separasi kemudian terbentuk vorticity yang banyak dipengaruhi oleh adanya adverse pressure gradient dan shear stress (gaya viskos) serta gaya-gaya aerodinamik seperti drag force dan lift force (Roshko A., 1953). Diketahui bahwa fenomena aliran yang mengarah pada terbentuknya periodic vortex flow dapat meningkatkan heat transfer (Sanijai, S., and Goldstein, R.J.,2004), dalam hal ini adalah dapat meningkatkan nilai dari Nusselt number, dimana Nusselt number merupakan parameter yang mengindikasikan terjadinya proses heat transfer yang nilainya sangat dipengaruhi oleh Reynolds number dan Prandtl number (Sarkar, S., et.al., 2011).

Modifikasi turbulent viscosity (Durbin,P.A., 1996) dimaksudkan untuk mereduksi perhitungan level turbulen dengan cara menaikkan produksi disipasi energi atau menurunkan produksi turbulent kinetic energy (Medic, G. dan Durbin,P.A., 2002). Penelitian yang telah dilakukan dengan memodifikasi turbulent viscosity digunakan untuk mengananalisis perpindahan panas pada titik stagnasi (Szczepanic, K.,et.al., 2004).

Separasi aliran yang melewati permukaan tube bundles arrangement (tubes array) dapat menaikkan terjadinya proses perpindahan panas yang sebanding dengan naiknya Reynolds number. Naiknya heat transfer ditunjukkan dengan meningkatnya nilai Nusselt number ( $\mathrm{Nu}$ ) (El Gharbi, N., et.al.,2015).

Studi ini menggunakan parameter data hasil eksperimen (Scholten, J.W. dan Murray,D.B., 1998) yang akan dibandingkan dengan data hasil simulasi numerik. Reynolds number eksperimen sebesar $\operatorname{Re}_{\mathrm{D}}=35950$, diameter silinder sirkular (D) 25 $\mathrm{mm}$, turbulence intensity $\mathrm{Tu}=0.34 \%$, kecepatan $\mathrm{v}=25 \mathrm{~m} / \mathrm{s}$, Strouhal number $\mathrm{St}=$ 0.16, frekuensi $216 \mathrm{~Hz}$. Property fluida menggunakan udara $\mathrm{Pr}=0.7$, dengan kondisi temperatur dinding silinder sirkular dijaga konstan pada temperatur $\mathrm{T}_{\mathrm{w}} 310{ }^{\circ} \mathrm{C}$, temperatur freestream $\mathrm{T}_{\sim}=28^{\circ} \mathrm{C}$. Pengukuran eksperimen pada Nusselt number front stagnation point diperoleh hasil sebesar $\mathrm{Nu}_{\mathrm{fsp}}=184$.

Tujuan dari penelitian ini adalah untuk mengetahui pengaruh modifikasi turbulent viscosity pada hasil simulasi numerik dengan membandingkan data hasil simulasi dengan data hasil eksperimen pada silinder tunggal dan untuk memprediksi nilai Nusselt number pada silinder tandem.

\section{Metodologi Penelitian}

\section{Persamaan Dasar Aliran Fluida dan Perpindahan Panas}

Pada studi ini, aliran diasumsikan sebagai 2-D (dua dimensi), fully developed, external flow, setting simulasi steady dan unsteady, incompressible of Newtonian fluid dan viscous fluid. Persamaan dasar aliran dan perpindahan panas:

- Mass Conservation

$$
\frac{\partial \rho}{\partial \mathrm{t}}+\nabla(\rho \mathrm{u})=0
$$

- Continuity

$$
\nabla \cdot \mathrm{u}=0
$$

- Momentum Conservation (Navier Stokes) 


$$
\frac{\partial \mathrm{u}}{\partial \mathrm{t}}+(\mathrm{u} . \nabla) \mathrm{u}=-\frac{1}{\rho} \nabla \mathrm{p}-\mathrm{g}+v \nabla^{2} \mathrm{u}
$$

- Energy

$$
\rho \operatorname{Cp} \frac{\partial \mathrm{T}}{\partial \mathrm{t}}+\rho \operatorname{Cp}(\text { u. } \nabla) \mathrm{T}=\mathrm{k} \nabla^{2} \mathrm{~T}
$$

- Nusselt Number

$$
N u=\frac{\mathrm{h}_{\text {conv }} \mathrm{D}}{\mathrm{k}_{\text {fluid }}}
$$

\section{Model dan Setting Simulasi}

Simulasi menggunakan metode RANS (Reynolds-averaged Navier-Stokes) model, software FLUENT 6.3 dengan 3 model turbulen yaitu standard $k$ - $\epsilon$, standard $k-\omega$, dan SST $k-\omega$ turbulence models.Computation domain dibuat sesuai dengan geometri kasus dari aliran fluida dan perpindahan panas yang akan diteliti, yaitu aliran melintasi (cross flow) silinder sirkular tunggal dan tandem. Model meshing menggunakan quadrilateral map yang dibuat dengan software GAMBIT 2.4. Sebelum melakukan simulasi pada FLUENT, maka harus dilakukan setting sesuai kasus dan parameter data yang akan disimulasikan. Dalam studi ini menngunakan parameter data eksperimen. Computation domain, model meshing dan setting simulasi ditunjukkan pada tabel 1 .

Tabel 1. Computation Domain, Model Meshing dan Setting Simulasi

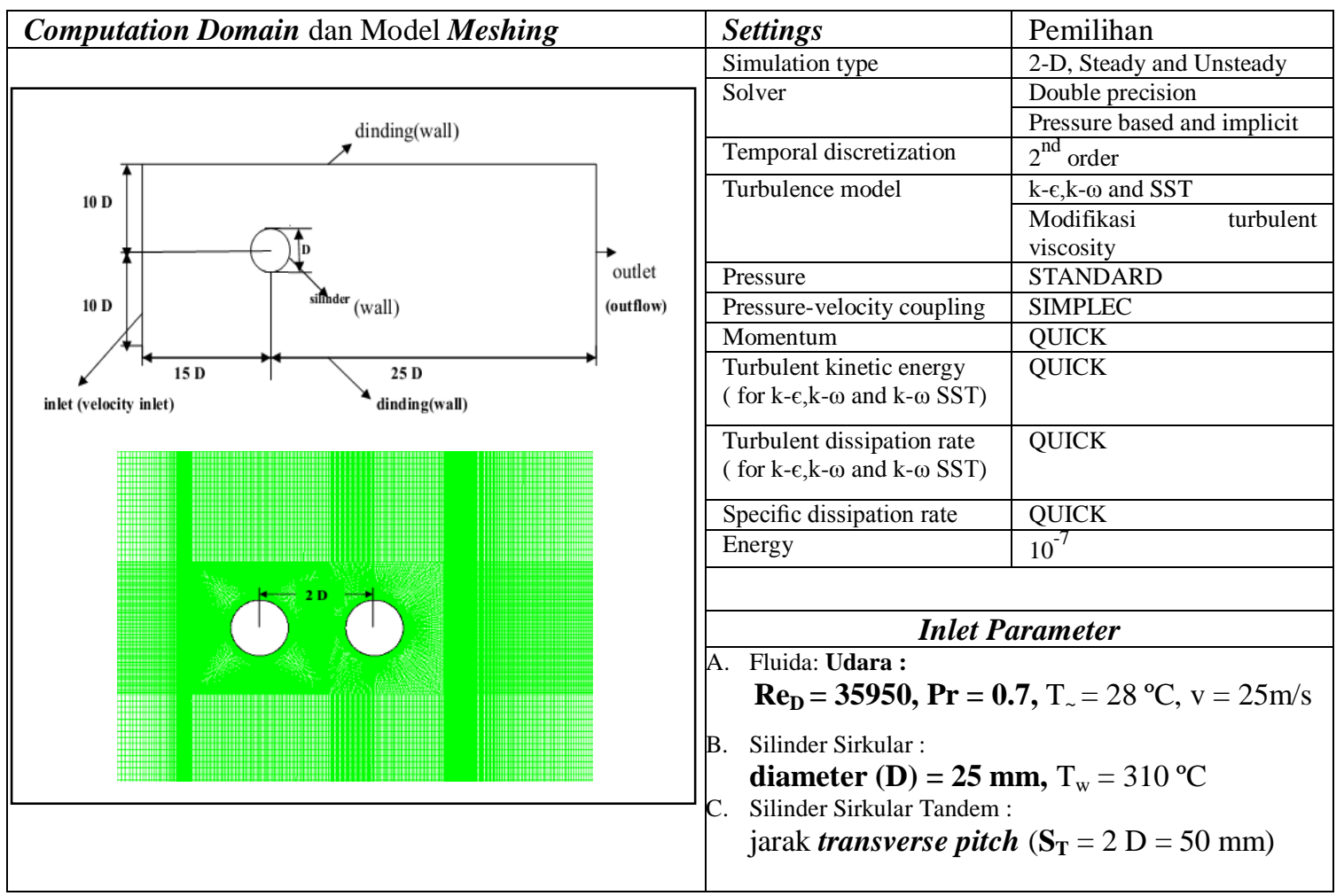

\section{Modifikasi Turbulent Viscosity}

Turbulence model yang dipakai pada studi ini adalah standard k- $\epsilon$, standard k- $\omega$, dan SST k- $\omega$ turbulence models. Pada standard k- $\epsilon$ dan standard k- $\omega$ dilakukan modifikasi turbulent viscosity (Durbin,P.A., 1996), (Medic,G. dan Durbin,P.A., 2002), sedangkan pada SST k- $\omega$ menggunakan persamaan dasarnya dan tanpa melakukan modifikasi. 
Modifikasi turbulent viscosity pada standard k-€:

- Turbulent Kinetic Energy $(k)$

$\partial_{t}(\rho k)+\nabla \cdot(\rho U k)=\rho P_{k}-\rho \varepsilon+\nabla \cdot\left(\left(\mu+\mu_{t}\right) \nabla k\right.$,

dimana:

$\rho P_{k}=R: \nabla U=-\frac{2}{3} \rho k(\nabla \cdot U)+2 \mu_{t}|S|^{2}-\frac{2}{3} \mu_{t}(\nabla \cdot U)^{2}$

dengan $S_{i j}=1 / 2\left(\partial_{j} U_{i}+\partial_{i} U_{j}\right)$

- Dissipation ( $\epsilon)$

$$
\partial_{t}(\rho \varepsilon)+\nabla \cdot(\rho U \varepsilon)=\frac{C_{\varepsilon 1} \rho P_{k-} C_{\varepsilon 2} \rho \varepsilon}{T}+\nabla \cdot\left(\left(\mu+\frac{\mu_{t}}{\sigma_{\varepsilon}}\right) \nabla \varepsilon\right.
$$

- Turbulent viscosity(Eddy viscosity)

$\mu_{t}=C_{\mu} \rho k T_{t}$

- Turbulent Time Scale $\left(T_{t}\right)$

$T_{t}=\min \left[\frac{k}{\varepsilon}, \frac{2}{3 C_{\mu}} \sqrt{\frac{3}{8|S|^{2}}}\right]$

- Model Konstan

$\mathrm{C}_{\varepsilon 1}=1.44 ; \mathrm{C}_{\varepsilon 2}=1.92 ; \sigma_{\varepsilon}=1.3 ; \mathrm{C}_{\mu}=0.09$

Modifikasi turbulent viscosity pada standard $k-\omega$ :

- $\quad$ Turbulent Kinetic Energy $(k)$

$\partial_{t}(\rho k)+\nabla \cdot(\rho U k)=\rho P_{k}-C_{\mu} \rho \omega k+\nabla \cdot\left(\left(\mu+\sigma_{k} \mu_{t}\right) \nabla k\right)$,

dimana:

$\rho P_{k}=R: \nabla U=-\frac{2}{3} \rho k(\nabla \cdot U)+2 \mu_{t}|S|^{2}-\frac{2}{3} \mu_{t}(\nabla \cdot U)^{2}$

dengan: $\mathrm{S}_{\mathrm{ij}}=1 / 2\left(\partial_{\mathrm{j}} \mathrm{U}_{\mathrm{i}}+\partial_{\mathrm{i}} \mathrm{U}_{\mathrm{j}}\right)$

- Spesific Dissipation Rate ( $\omega)$

$\left.\partial_{t}(\rho \omega)+\nabla \cdot(\rho U \omega)=\frac{1}{T}\left(\frac{\gamma_{1}}{C_{\mu} k} \rho P_{k}-\frac{\beta_{1}}{C_{\mu}} \rho \omega\right)+\nabla \cdot\left(\mu+\sigma_{\omega} \mu_{t}\right) \nabla_{\omega}\right)$

- Turbulent viscosity(Eddy viscosity)

$\mu_{t}=C_{\mu} \rho k T_{t}$

- TurbulentTime Scale $\left(T_{t}\right)$

$$
T_{t}=\min \left[\frac{1}{c_{\mu} \omega}, \frac{\alpha}{\sqrt{6} C_{\mu}|S|}\right]
$$

- Model Konstan

$\sigma_{\mathrm{k}}=0.5 ; \sigma_{\omega}=0.5 ; \gamma_{1}=5 / 9 ; \beta_{1}=0.075 ; \mathrm{C}_{\mu}=0.09$

\section{Hasil dan Pembahasan}

\section{Karakteristik Aliran}

Karakteristik aliran pada regime sub-critical $\mathrm{Re}_{\mathrm{D}}=35950$ ditandai dengan adanya titik stagnasi, separasi, shear layer dan periodic vortex. Shear layer pada bagian atas dan bawah permukaan silinder menggulung(berotasi) membentuk small-scale vortices(eddy) disertai terbentuknya laminar boundary layer yang terseparasi melalui upstream bagian depan silinder. Pada downstream di belakang silinder sirkular terjadi turbulent wake dan periodic vortec seperti tampak pada gambar $1 \mathrm{~A}$. 
Pengaruh dari metode modifikasi turbulent viscosity adalah bahwa modifikasi turbulent viscosity dapat menurunkan besarnya nilai turbulent kinetic energy, atau dalam hal ini adalah dapat meningkatkan terjadi disipasi. Kondisi ini dapat diperjelas dengan melihat kontur level turbulent kinetic energy seperti terlihat pada gambar $1 \mathrm{~B}$.
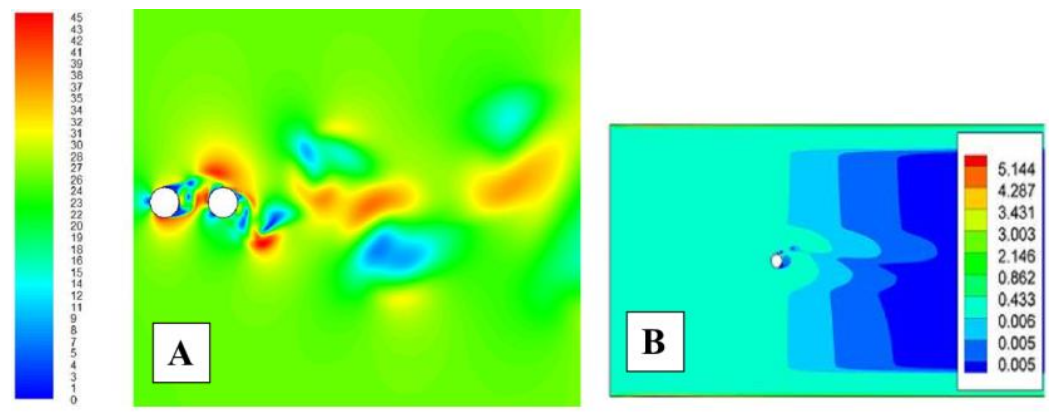

Gambar 1: A. Kontur aliran pada unsteady k- $\omega$ SST turbulent model silinder tandem

Gambar 1: B. Kontur Level turbulent kinetic energy pada steady standard k-€ turbulent model (dengan modifikasi turbulent viscosity) silinder tunggal

\section{Hasil Simulasi Numerik Perpindahan Panas}

Istilah yang dipakai pada studi numerik ini adalah T-Lim (T-Limited) yang menunjukkan bahwa model turbulen yang dipakai dalam bentuk modifikasi. Sedangkan T-Ave menunjukkan bahwa simulasi dilakukan pada kondisi unsteady.

Pada gambar $1 \mathrm{C}$ (silinder tunggal) dan gambar $1 \mathrm{D}$ (silinder tunggal) terlihat jelas bahwa heat transfer yang terjadi sebelum dilakukan modifikasi pada turbulent viscosity hasil simulasi menunjukkan nilai yang berada di atas hasil data eksperimen baik pada aliran steady dan unsteady. Sedangkan hasil simulasi yang menggunakan modifikasi pada turbulent viscosity menunjukkan hasil yang sangat signifikan dimana nilainya hampir mendekati hasil pada eksperimen terutama nilai heat transfer pada titik stagnasi Nusselt number front stagnation point $\left(\mathrm{Nu}_{\mathrm{fsp}}\right)$.

Dari gambar $1 \mathrm{~B}$ tampak jelas bahwa simulasi numerik yang menggunakan metode modifikasi turbulent viscosity dapat menurunkan level turbulent kinetic energy terutama di titik stagnasi, sedangkan pada wake region juga berpengaruh tapi tidak terlalu signifikan jika dibandingkan pengaruhnya di titik stagnasi.

Besarnya nilai heat transfer yang terjadi pada aliran yang melintasi silinder sirkular tunggal pada titik stagnasi ada hubungannya dengan besarnya heat flux, yang dirumuskan dengan persamaan sbb:

$$
\dot{q}_{t}=\frac{\mu_{t} C_{p}}{P r_{t}} \nabla T
$$

dimana $\mathrm{T}=$ temperatur $\left({ }^{\circ} \mathrm{C}\right)$ 

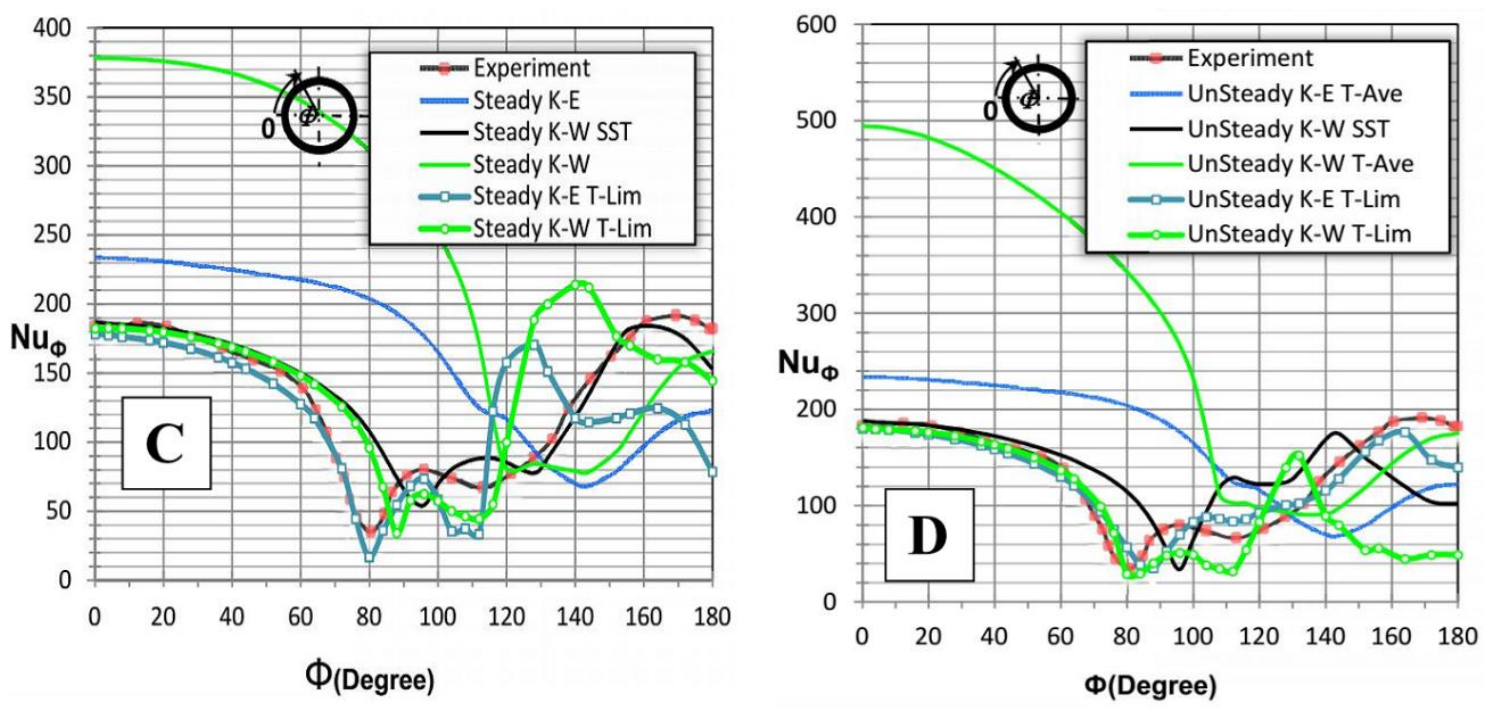

Gambar 1: C. Surface Nusselt number $\left(\mathrm{Nu}_{\Phi}\right)$ silinder tunggal pada $\mathrm{Re}_{\mathrm{D}}=35950$ hasil simulasi steady dengan dan tanpa modifikasi, serta data eksperimen

Gambar 1: D. Surface Nusselt number $\left(\mathrm{Nu}_{\Phi}\right)$ silinder tunggal pada $\mathrm{Re}_{\mathrm{D}}=35950$ hasil simulasi unsteady dengan dan tanpa modifikasi, serta data eksperimen

Dari persamaan ini dapat dipahami bahwa dengan memodifikasi $\mu_{\mathrm{t}}$ (turbulent viscosity) yaitu pada parameter T-Limited atau pada parameter Turbulent Time Scale $\left(T_{t}\right)$ dapat berpengaruh untuk mereduksi besarnya heat transfer yang terjadi. Besarnya perbandingan nilai Nusselt number front stagnation point $\left(\mathrm{Nu}_{\mathrm{fsp}}\right)$ hasil simulasi silinder tunggal dan eksperimen bisa dilihat pada tabel 2 sbb:

Tabel 2. Perbandingan nilai $\mathrm{Nu}_{\mathrm{fsp}}$ silinder tunggal hasil simulasi dan eksperimen

\begin{tabular}{|c|c|}
\hline $\mathrm{Nu}_{\mathrm{fsp}}$ eksperimen $=184$ & Perbedaan \\
\hline Steady Standard k-€ $\left(\mathrm{Nu}_{\mathrm{fsp}}=233.48\right)$ & $26,89 \%$ \\
\hline Unsteady Standard k- $\epsilon \quad\left(\mathrm{Nu}_{\mathrm{fsp}}=233.48\right)$ & $26,89 \%$ \\
\hline Standard k- $\epsilon$ T-Lim $\left(\mathrm{Nu}_{\mathrm{fsp}}=178.28\right)$ & $3,1 \%$ \\
\hline Unsteady Standard k- $\epsilon$ T-Lim $\left(\mathrm{Nu}_{\mathrm{fsp}}=180.28\right)$ & 0,02 \\
\hline Steady Standard $\mathrm{k}-\omega\left(\mathrm{Nu}_{\mathrm{fsp}}=378.32\right)$ & $105,6 \%$ \\
\hline Unsteady Standard k- $\omega\left(\mathrm{Nu}_{\mathrm{fsp}}=494.37\right)$ & $168,7 \%$ \\
\hline Standard k- $\omega$ T-Lim $\left(\mathrm{Nu}_{\mathrm{fsp}}=182.32\right)$ & $0,91 \%$ \\
\hline Unsteady Standard k- $\omega$ T-Lim $\left(\mathrm{Nu}_{\mathrm{fsp}}=181.29\right)$ & $1,47 \%$ \\
\hline Steady k- $\omega$ SST $\left(\mathrm{Nu}_{\mathrm{fsp}}=187.28\right)$ & $1,78 \%$ \\
\hline Unsteady k-w SST ( $\left.\mathrm{Nu}_{\mathrm{fsp}}=188.35\right)$ & $2,36 \%$ \\
\hline
\end{tabular}

Dari tabel 2 dapat diketahui bahwa modifikasi turbulent viscosity memberikan pengaruh yang cukup signifikan pada proses terjadinya heat transfer di titik stagnasi. Yang menarik adalah pemodelan menggunakan k- $\omega$ SST dapat memprediksi perpindahan panas di titik stagnasi dengan hasil yang cukup akurat meskipun tanpa menggunakan modifikasi turbulent viscosity. 

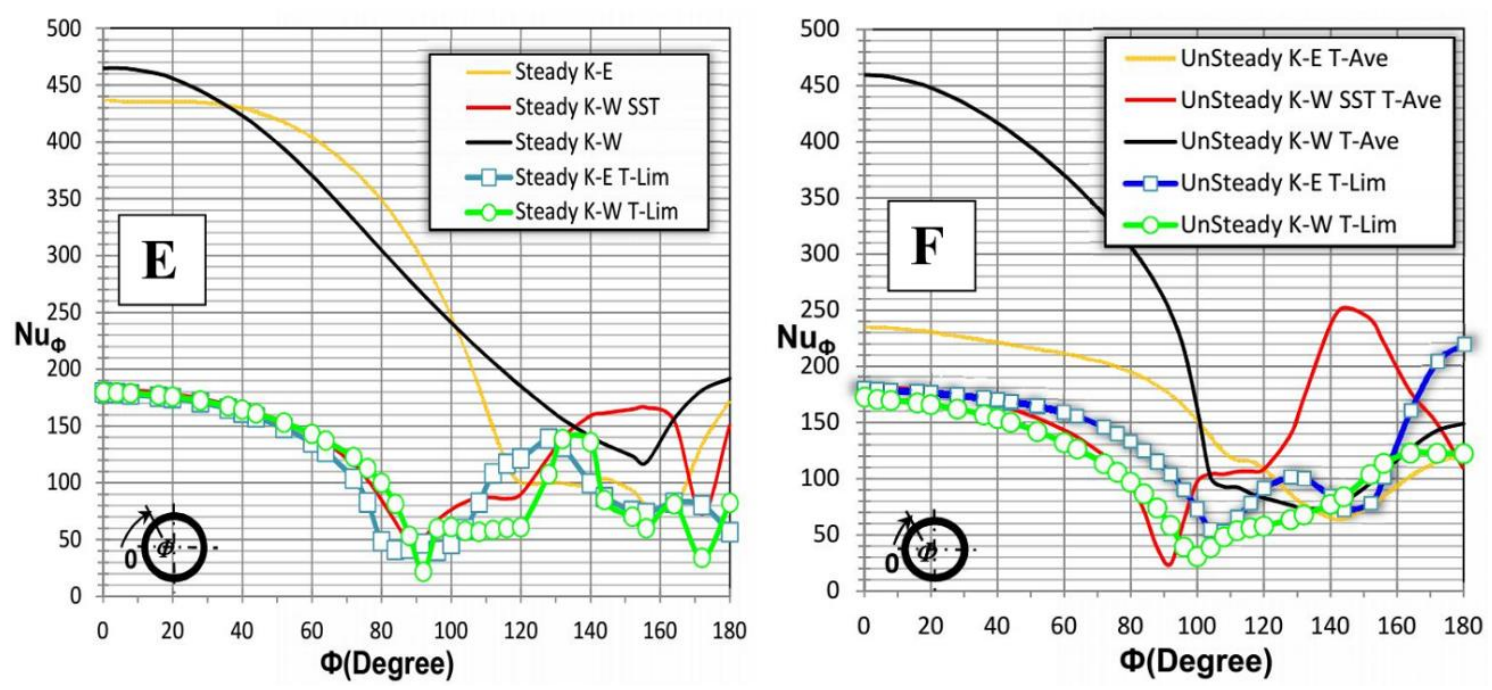

Gambar 1: E. Surface Nusselt number $\left(\mathrm{Nu}_{\Phi}\right)$ silinder tandem tube 1 pada $\mathrm{Re}_{\mathrm{D}}=35950$ hasil simulasi steady dengan dan tanpa modifikasi

Gambar 1 F. Surface Nusselt number $\left(\mathrm{Nu}_{\Phi}\right)$ silinder tandem tube 1 pada $\mathrm{Re}_{\mathrm{D}}=35950$ hasil simulasi unsteady dengan dan tanpa modifikasi
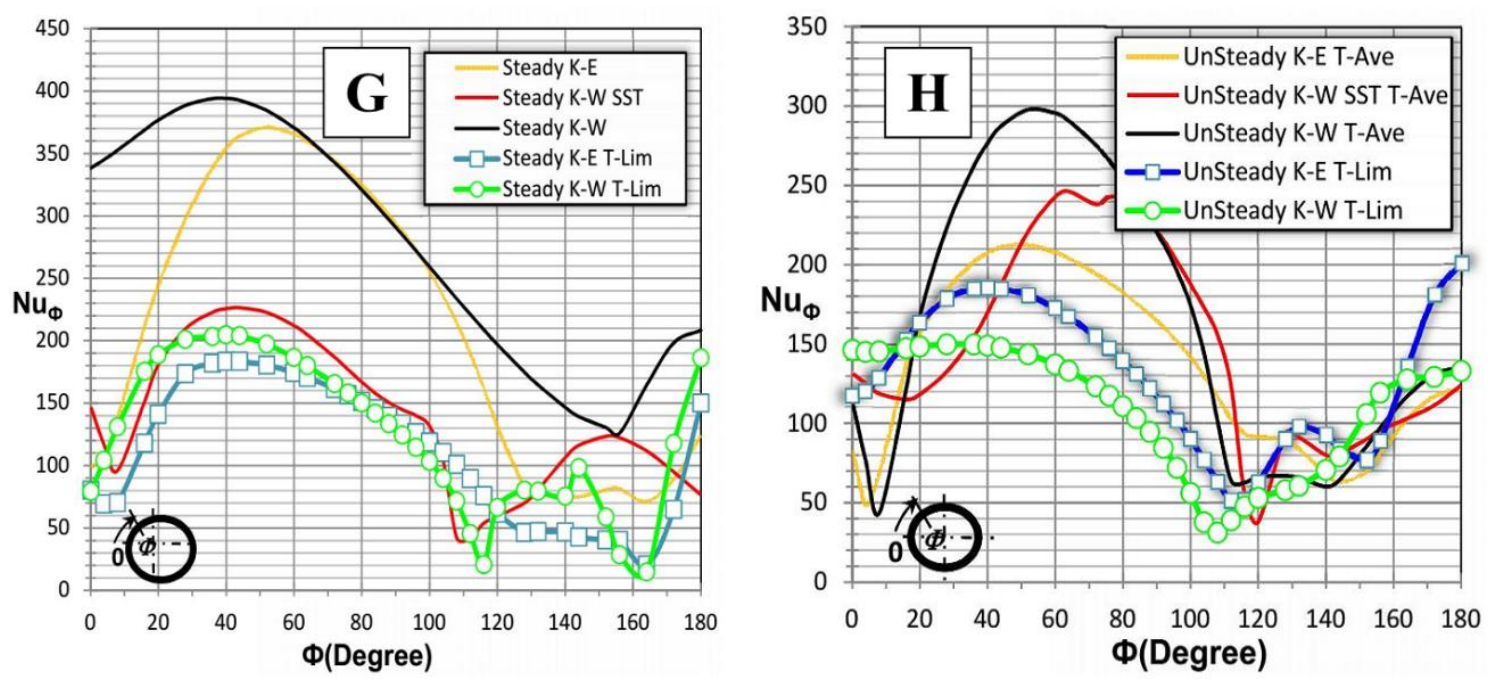

Gambar 1: G. Surface Nusselt number $\left(\mathrm{Nu}_{\Phi}\right)$ silinder tandem tube 2 pada $\mathrm{Re}_{\mathrm{D}}=35950$ hasil simulasi steady dengan dan tanpa modifikasi

Gambar 1 H. Surface Nusselt number $\left(\mathrm{Nu}_{\Phi}\right)$ silinder tandem tube 2 pada $\operatorname{Re}_{\mathrm{D}}=35950$ hasil simulasi unsteady dengan dan tanpa modifikasi

Setting simulasi pada silinder tunggal digunakan sebagai validasi simulasi pada silinder tandem untuk memprediksi hasil Nusselt number yang terjadi. Pada gambar $1 \mathrm{E}$ (tube 1) dan gambar $1 \mathrm{~F}$ (tube 1) tampak jelas bahwa nilai Nusselt number front stagnation point $\left(\mathrm{Nu}_{\mathrm{fsp}}\right)$ pada simulasi yang tanpa menggunakan modifikasi turbulent viscosity memberikan hasil yang tidak sama atau kurang akurat dibandingkan jika simulasi yang menggunakan modifikasi turbulent viscosity. Khusus untuk simulasi yang model k- $\omega$ SST memberikan hasil yang sama dengan simulasi yang menggunakan modifikasi turbulent viscosity, yaitu nilai Nusselt number front stagnation point sekitar $\mathrm{Nu}_{\mathrm{fs}}=185$ dan separasi aliran terjadi sekitar pada sudut $\Phi=90^{\circ}$. Pada gambar $1 \mathrm{G}$ (tube 2) terjadi kenaikan nilai Nusselt number pada sudut $\Phi=45$ karena adanya aliran reattachment yang disebabkan separasi aliran pada tube 1. Simulasi yang menggunakan modifikasi turbulent viscosity dan model k- $\omega$ SST memberikan hasil nilai Nusselt 
number yang hampir sama sekitar 160 sampai dengan 180, tetapi pada gambar $1 \mathrm{~F}$ (tube 2) simulasi model k- $\omega$ SST memberikan perbedaan hasil yang cukup signifikan.

Dari gambar $1 \mathrm{E}, 1 \mathrm{~F}$ (tube 2) dan gambar $3 \mathrm{G}, 3 \mathrm{~F}$ (tube 2) terlihat bahwa di bagian downstream silinder terjadi kenaikan nilai Nusselt number, yaitu bagian setelah terjadinya separasi aliran pada sudut sekitar $\Phi=110^{\circ}$ sampai $120^{\circ}$. Hal ini terjadi karena pada bagian itu mixing aliran lebih sering terjadi yang ditandai dengan terjadi vortex shedding, periodic vortec dan turbulent wake.

\section{Kesimpulan}

Pengaruh penggunaan metode modifikasi dapat menurunkan besarnya level turbulent kinetic energy, sehingga juga mereduksi besarnya nilai heat transfer. Jika diaplikasikan pada simulasi numerik hasilnya adalah dapat memberikan prediksi yang lebih akurat pada proses perpindahan panas di titik stagnasi. Model turbulen k- $\omega$ SST bisa digunakan untuk memprediksi proses perpindahan panas pada aliran yang melintasi silinder sirkular tunggal dan tandem dengan hasil yang cukup akurat meskipun tanpa menggunakan modifikasi turbulent viscosity pada $\mathrm{Re}_{\mathrm{D}}$ yang cukup tinggi di sub-critical regime. Untuk memprediksi proses perpindahan panas aliran yang melintasi silinder sirkular tunggal dan tandem yang menggunakan model turbulen standard k- $\epsilon$ dan standard k- $\omega$ baik aliran steady dan unsteady hasilnya akan lebih akurat jika menggunakan metode modifikasi turbulent viscosity pada Reynolds number $\left(\mathrm{Re}_{\mathrm{D}}\right)$ yang cukup tinggi.

\section{Ucapan Terima Kasih}

\section{Daftar pustaka}

Beaudan, P. and Moin, P. (1994), Numerical Experiments on The Flow past a Circular Cylinder at Sub-Critical Reynolds Number, Research in Stanford University California.

Durbin,P.A. (1996), On the k-e stagnation point anomaly, International Journal Heat and Fluid Flow, Vol. 17, no.1, February 1996

El Gharbi, N., et.al. (2015), Numerical optimization oh heat exchangers with circular and non-circular shapes, Case Studies in Thermal Engineering 6 (2015) 194-203

Kieft, R., et.al. (2007), Near-wake effects effects of a heat input on the vortex-shedding mechanism, International Journal of Heat and Fluid Flow 28 (2007) 938-947.

Lowery, G.W. and Vachon, R.I. (1974). The Effect of Turbulence on Heat Transfer from Heated Cylinder, International Journal of Heat and Mass Transfer, Vol. 18:p. 1229-1242

Medic,G. and Durbin,P.A. (2002), Toward Improved Prediction of Heat Transfer on Turbine Blades, Journal of Turbomachinery, 2002, Vol. 124, 187-192.

Roshko A. (1953), On the Development of Turbulent Wakes From Vortex Streets, (1953) Supersedes NACA TN 2913.

Sarkar, S., et.al. (2011), Unsteady wake dynamics and heat transfer in forced and mixed convection past a circular cylinder in cross flow for high Prandtl numbers, International Journal of Heat and Mass Transfer 54 (2011)3536-3551.

Szczepanic, K.,et.al. (2004), A Numerical Study of Heat Transfer from a Cylinder in Crossflow, $15^{\text {th }}$ Australasian Fluid Mechanics Conference, 13-17 December 2004 
90 Arif Kurniawan, et al.

Sanijai, S., and Goldstein, R.J. (2004), Forced convection heat transfer from a circular cylinder in crossflow to air and liquids, International Journal of Heat and Mass Transfer 47 (2004) 4795-4805.

Scholten, J.W. and Murray,D.B. (1998), Unsteady Heat Transfer and Velocity of a Cylinder in Cross Flow - I. Low Freestream Turbulence, International Journal of Heat and Mass Transfer, 1998, 41, (10), 1139-1148. 